subjects achieving PASI-75/PASI-50 among those with psoriasis involvement $\geq 3 \%$ of the body surface area at baseline, and dactylitis count and MASES of 0 among those with dactylitis or enthesitis at baseline. Safety is described for the overall PALACE 1-3 population.

Results: A total of 109 subjects randomised to APR30 treatment at baseline were ACR20NRs at Week 104. Baseline ACR core components were similar for ACR20NRs and ACR20 responders at Week 104. Among these ACR20NRs, several core components of ACR response, including swollen/tender joint counts and Physician's Global Assessment of Disease Activity (visual analogue scale) scores, showed sustained improvements from baseline through Week 104 (table 1). Importantly, of the 109 ACR20NRs at Week $104,50.0 \%$ achieved a PASI-50 response after continued treatment with APR30 through Week 104 (table 1). Among ACR20NRs with baseline dactylitis $(n=44)$ or enthesitis $(n=74), 68.2 \%$ achieved a dactylitis count of $0 \%$ and $33.8 \%$ achieved a MASES of 0 at Week 104. More limited improvements in Subject's Global Assessment of Disease Activ ity, Subject's Assessment of Pain, Health Assessment Questionnaire-Disability Index, and C-reactive protein outcomes most commonly had an impact on subjects' ability to achieve an ACR20 response. In the overall subject population, no new safety concerns were identified through 104 weeks.

Abstract OP0309 - Table 1

\begin{tabular}{|c|c|c|c|}
\hline & \multicolumn{3}{|c|}{$\begin{array}{c}\text { ACR20NRs at Week } 104 \\
\text { With APR30 From Baseline }(n=109)\end{array}$} \\
\hline & & & \\
\hline Swollen joint count (0-76), mean and median $\%$ change & $-52.2,-71.4$ & $-62.8,-73.3$ & $-58.0,-75.0$ \\
\hline Tender joint count $(0-78)$, mean and median $\%$ change & $-32.5,-47.4$ & $-45.8,-53.5$ & $-41.7,-51.7$ \\
\hline phGA (VAS 0-100 $\mathrm{mm}$ ), mean and median $\%$ change & $-37.9,-43.6$ & $-49.8,-54.2$ & $-44.3,-48.7$ \\
\hline Dactblitis $=0, n / m(\%)^{*}$ & $23 / 44(52.3)$ & $29 / 44(65.9)$ & $30 / 44(68.2)$ \\
\hline MASES $=0, n / m(\%)^{5}$ & $20 / 74(27.0)$ & $27 / 74(36.5)$ & $25 / 74(33.8)$ \\
\hline PASI-75, n/m $(\%)^{ \pm}$ & $17 / 50(34.0)$ & $22 / 50(44.0)$ & $18 / 50(36.0)$ \\
\hline PASI- $50, n / m(\%)^{ \pm}$ & & & \\
\hline \multicolumn{4}{|c|}{$\begin{array}{l}\text { Data are as observed at Week } 24 \text {, Week } 52 \text {, and Week } 104 \text { for all subjects who were randomized to } \\
\text { APR30 at baseline and were ACR20NRs at Week } 104 \text { and with a value at the time point indicated. } \\
\text { *Examined among subjects with dactylitis at baseline. SExamined among subjects with enthesitis at } \\
\text { baseline. FExamined among subjects with } 23 \% \text { psoriasis involvement of the body surface area at } \\
\text { baseline. PhGA=Physician's Global Assessment of Disease Activity; VAS }=\text { visual analog scale; } \\
\text { n/m=number of subjects achieving response/number of subjects with evaluable data at the time point, } \\
\text { MASES=Maastricht Ankylosing Spondylitis Enthesitis Score; PASI-75/50 }=275 \% / 250 \% \text { reduction from } \\
\text { baseline Psoriasis Area and Severity Index score. }\end{array}$} \\
\hline
\end{tabular}

Conclusions: ACR20NRs receiving APR30 demonstrated significant improvements in core PsA domains. The data may explain why subjects who failed to achieve an ACR20 response remained on long-term APR treatment. These findings suggest that some subjects with PsA may experience meaningful clinical improvement that is not completely captured by the assessment of ACR20 response criteria. Outcome measures specifically designed for PsA subjects, may be more suitable to evaluate treatment response in PsA subjects.

Disclosure of Interest: P. Mease Grant/research support from: Abbott, Amgen, Biogen Idec, BMS, Celgene Corporation, Genentech, Janssen, Eli Lilly, Novartis, Pfizer, Roche, UCB, Consultant for: Abbott, Amgen, Biogen Idec, BMS, Celgene Corporation, Genentech, Janssen, Eli Lilly, Novartis, Pfizer, Roche, UCB, Speakers bureau: Abbott, Amgen, Biogen Idec, BMS, Genentech, Janssen, Eli Lilly, Pfizer, UCB, D. Gladman Grant/research support from: AbbVie, Amgen, BMS, Celgene Corporation, Janssen, Novartis, Pfizer, UCB, Consultant for: AbbVie, Amgen, BMS, Celgene Corporation, Janssen, Novartis, Pfizer, UCB, A. Kavanaugh Grant/research support from: Abbott, Amgen, AstraZeneca, BMS, Celgene Corporation, Centocor-Janssen, Pfizer, Roche, UCB, P. Nakasato Employee of: Celgene Corporation, B. Guerette Employee of: Celgene Corporation, L. Teng Employee of: Celgene Corporation, P. Nash Grant/research support from: Celgene Corporation

DOI: 10.1136/annrheumdis-2018-eular.2705

\section{OP0310 PREVALENCE OF RISK FACTORS AND CARDIOVASCULAR EVENTS ACROSS PSORIATIC ARTHRITIS PATIENTS TREATED WITH BIOLOGICAL THERAPY}

F. Maceiras-Pan ${ }^{1}$, C. García-Porrúa ${ }^{2}$, J.A. Mosquera-Martinez ${ }^{3}$, L. FernandezDominguez $^{4}$, B. Correa-Rey ${ }^{5}$, M. Pombo-Suarez ${ }^{6}$, J. Pinto-Tasende ${ }^{7}$. ${ }^{1}$ Rheumatology, CHU Vigo, Vigo; ${ }^{2}$ Rheumatology, HU Lucus Augusti, Lugo; ${ }^{3}$ Rheumatology, CHU Pontevedra, Pontevedra; ${ }^{4}$ Rheumatology, CHU Ourense, Ourense; ${ }^{5}$ Rheumatology, CHU Arquitecto Marcide-Naval, Ferrol; ${ }^{6}$ Rheumatology, CHU Santiago, Santiago de Compostela; ${ }^{7}$ Rheumatology, INIBIC-XXI A Coruña, A Coruña, Spain

Background: Psoriasis and psoriatic arthritis (PsA) are described as associated with more frequency of risk factors and cardiovascular events.

Objectives: To determine the prevalence of risk factors and cardiovascular events in a cohort of patients with PsA treated with biological therapy and its correlation with gender.

Methods: We included all PsA patients (met CASPAR criteria) following treatment with bDMARDs (reference population 2.055.000). We obtained data of high blood pressure, hyperlipidemia, hyperuricemia, type 2 diabetes mellitus, obesity $(\mathrm{BMI} \geq 30)$, non-infectious liver disease, ischaemic cardiopathy, myocardial infarction, ischaemic stroke or transient ischaemic attack. For this analysis included gender, age, disease duration, current bDMARDs with or without current co-medication with csDMARDs and HLA-B27 status. Continuous variables were reported as mean \pm standard deviation. Categorical variables were reported as percentages and frequencies. All analyses were performed using SPSS software. Differences were considered statistically significant if $p<0.05$ (two-tailed).

Results: Data were obtained from 598 PsA patients who have been treated with bDMARDs. Three-hundred and twenty-five (54.3\%) patients were men, mean age was $53.3 \pm 12.6$ years (men $53.3 \pm 12.9$ and women $53.2 \pm 12.3, p=0.943$ ) and dis ease duration of PsA was $12.4 \pm 8.7$ years. No differences were seen for disease duration of PsA, nail disease, dactylitis, uveitis or HLA-B27. The prevalence of high blood pressure, hyperlipidemia, hyperuricemia, type 2 diabetes mellitus, obesity, non-infectious liver disease, ischaemic cardiopathy, myocardial infarction (MI) and ischaemic stroke/transient ischaemic attack (IS) was 36.0\%, 43.6\%, $16.0 \%, 12.5 \%, 26.3 \%, 12.5 \%, 5.5 \%, 3.8 \%$ and $1.3 \%$, respectively. Men had most prevalence of type 2 diabetes mellitus, hyperuricemia, non-infectious liver disease, ischaemic cardiopathy, myocardial infarction and brain stroke event (see table 1). Patients with MI or IS had more prevalence of CV risk factors.

Abstract OP0310 - Table 1

\begin{tabular}{lccc}
\hline & $\begin{array}{c}\text { Female } \\
(273)\end{array}$ & $\begin{array}{c}\text { Male } \\
(325)\end{array}$ & $\mathrm{P}$ \\
\hline High blood pressure, $\mathrm{n}(\%)$ & $98(35.9)$ & $117(36.0)$ & 0.979 \\
Hyperlipidemia, $\mathrm{n}(\%)$ & $111(40.7)$ & $150(46.2)$ & 0.177 \\
Hyperuricemia, $\mathrm{n}(\%)$ & $13(4.8)$ & $82(25.3)$ & $<0.001$ \\
Diabetes mellitus, $\mathrm{n}(\%)$ & $21(7.7)$ & $54(16.6)$ & 0.001 \\
Liver disease, $\mathrm{n}(\%)$ & $19(7.6)$ & $49(16.7)$ & 0.002 \\
Ischaemic cardiopathy, $\mathrm{n}$ & $8(2.9)$ & $25(7.7)$ & 0.011 \\
$(\%)$ & & & \\
Myocardial infarction, $\mathrm{n}(\%)$ & $5(1.8)$ & $18(5.5)$ & 0.019 \\
Brain stroke event, $\mathrm{n}(\%)$ & $1(0.2)$ & $7(2.2)$ & 0.058 \\
\hline
\end{tabular}

Conclusions: Type 2 diabetes mellitus, hyperuricemia, non-infectious liver disease, ischaemic cardiopathy, myocardial infarction and brain stroke event were more prevalent in men than in women with PsA. Male gender had correlation with the prevalence of cardiovascular events or their risk factors.

\section{REFERENCE:}

[1] Husted JA, et al. Cardiovascular and other comorbidities in patients with psoriatic arthritis: A comparison with patients with psoriasis. Arthritis Care Res (Hoboken) 2011 Dec;63(12):1729-35.

Acknowledgements: The authors are grateful for the support of the members of the Galician Society of Rheumatology (SOGARE)

Disclosure of Interest: None declared

DOI: 10.1136/annrheumdis-2018-eular.4922

\section{OP0311 NOTABLE EVOLUTIONS IN THE CHARACTERISTICS OF PSORIATIC ARTHRITIS CLINICAL TRIALS POPULATIONS IN THE ERA OF BIOLOGICAL TREATMENTS}

A.-S. Vandendorpe, K. De Vlam, R. Lories. Skeletal Biology and Engineering Research Center - Dept. Development and Regeneration, KU Leuven, Leuven, Belgium

Background: Psoriatic arthritis is a chronic inflammatory disease that affects the musculoskeletal system. It can include arthritis, spondylitis, dactylitis and enthesitis, and is strongly associated with the presence of psoriasis. The introduction of biological therapies as a treatment option has brought a significant improvement in disease control for these patients.

Objectives: In this study, we wanted to detect emerging differences in demographic and clinical characteristics of the PsA-patient study population since the introduction of biologicals

Methods: We selected 12 phase II- and phase III-trials and divided them into 3 treatment periods based on different time windows and working mechanisms of the particular biologicals or targeted DMARDs. Published tables with the baseline demographic and clinical characteristics of study population from the individual studies were used. For inclusion of a specific parameter, it had to be present in at least one study of each period. An exception to this rule was made for the 'number of patients with prior anti-TNF therapy', only present in studies from the second and third period. Parameters were defined in different categories: patient characteristics (gender, age, race, weight), disease characteristics (duration of PsA presence of dactylitis, presence of enthesitis, psoriasis body surface area), disease activity parameters (swollen joint count, tender joint count, C-reactive protein 